Article

\title{
Evaluation of Dimethyl Carbonate as Alternative Biofuel. Performance and Smoke Emissions of a Diesel Engine Fueled with Diesel/Dimethyl Carbonate/Straight Vegetable Oil Triple Blends
}

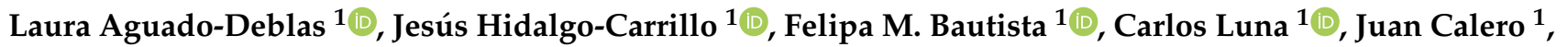 \\ Alejandro Posadillo ${ }^{2}$, Antonio A. Romero ${ }^{1}$ D , Diego Luna ${ }^{1, *}$ and Rafael Estévez ${ }^{1}$ \\ 1 Departamento de Química Orgánica, Universidad de Córdoba, Campus de Rabanales, Ed. Marie Curie, \\ 14014 Córdoba, Spain; aguadolaura8@gmail.com (L.A.-D.); Jesus.hidalgo@uco.es (J.H.-C.); \\ qo1baruf@uco.es (F.M.B.); qo2luduc@uco.es (C.L.); p72camaj@gmail.com (J.C.); qo1rorea@uco.es (A.A.R.); \\ q72estor@uco.es (R.E.) \\ 2 Seneca Green Catalyst S.L., Campus de Rabanales, 14014 Córdoba, Spain; seneca@uco.es \\ * Correspondence: diego.luna@uco.es; Tel.: +34-957212065
}

Citation: Aguado-Deblas, L.; Hidalgo-Carrillo, J.; Bautista, F.M.; Luna, C.; Calero, J.; Posadillo, A.; Romero, A.A.; Luna, D.; Estévez, R. Evaluation of Dimethyl Carbonate as Alternative Biofuel. Performance and Smoke Emissions of a Diesel Engine Fueled with Diesel/Dimethyl Carbonate/Straight Vegetable Oil Triple Blends. Sustainability 2021, 13, 1749. https://doi.org/10.3390/ su13041749

Academic Editor: Raffaele Cucciniello Received: 13 January 2021

Accepted: 2 February 2021

Published: 6 February 2021

Publisher's Note: MDPI stays neutral with regard to jurisdictional claims in published maps and institutional affiliations.

Copyright: (c) 2021 by the authors. Licensee MDPI, Basel, Switzerland. This article is an open access article distributed under the terms and conditions of the Creative Commons Attribution (CC BY) license (https:/ / creativecommons.org/licenses/by/ $4.0 /)$.

\begin{abstract}
Dimethyl carbonate (DMC) is an interesting blending component for diesel fuel (D) owing to the high oxygen content (53 wt.\%) and the absence of $\mathrm{C}-\mathrm{C}$ bonds in its structure. Moreover, DMC can be produced from $\mathrm{CO}_{2}$ and methanol, which provides a renewable way to reduce anthropogenic $\mathrm{CO}_{2}$. This research has been addressed to assess the use of DMC as a solvent of sunflower oil (SO) and castor oil (CO), with the purpose of obtaining biofuels that can replace fossil diesel as much as possible. The blending of DMC with straight vegetable oils (SVOs) reduces their high viscosity, allowing their usage as drop-in biofuels without chemical treatments. Based on viscosity requirements of European Standard EN 590, the optimal DMC/SVO double blends have been tested as direct biofuels by themselves or mixed with fossil diesel in D/DMC/SVO triple blends. Relevant physico-chemical properties of fuels have been analyzed. Engine parameters such as power output, brake-specific fuel consumption (BSFC) and soot emissions have been studied to determine the effect of new biofuels on efficiency of a diesel engine. An outstanding engine efficiency is shown by the studied D/DMC/SVO triple blends, either with SO or CO as an SVO. The low calorific value of DMC is the main reason for reduction in power and BSFC, as the amount of diesel in the triple blends is reduced. Experimental results demonstrate that the use of these biofuels allows the replacement of up to $40 \%$ of fossil diesel, without compromising the power and BSFC of the engine, and accomplishing optimal cold flow properties and a marked drop in exhaust emissions.
\end{abstract}

Keywords: dimethyl carbonate; straight vegetable oils; castor oil; sunflower oil; biofuel; oxygenated fuel; diesel engine; soot emissions; smoke opacity; power output

\section{Introduction}

The necessary climate change mitigation, along with the decreasing crude oil reserves, make gradual fossil fuel replacement mandatory. Electric, hybrid or hydrogen engines are emerging as future substitutes for conventional engines. However, the urgent need for reducing anthropogenic gases implies that the energy transition must also be carried out considering the engines installed in currently in-use vehicles [1]. This is especially important in certain transportation sectors such as aviation, maritime shipping or heavy vehicles, where the incorporation of new engines is still a challenge [2-4].

Nowadays, biodiesel, produced by transesterification of vegetable oils with methanol, is the most employed biofuel to replace diesel fossil fuel [5]. From a technical point of view, the substitution of diesel for biodiesel does not entail an issue. The major drawback is the obtention of glycerol during its production, which contaminates biodiesel and also 
generates huge amounts of this by-product that needs a clear commercial outlet, and this makes the biodiesel production process economically infeasible. Moreover, large quantities of agricultural products are used to produce biodiesel. Considering that the transport sector annually consumes a quarter of the total global primary energy on its own, the use of this biomass as feedstock for biofuel production endangers the agricultural resources destined for human and animal consumption, and generates competition for land use, increasing the prices in the market [6]. Thus, an intensive investigation into alternative fuels for diesel engines has been performed in recent years.

Straight vegetable oils (SVOs) are a promising alternative to replace fossil diesel. SVOs are obtained from renewable resources, available around the world and are also environmentally friendly. In fact, vegetable oils began to be used as fuels in 1900, when Rudolf Diesel used peanut oil in a diesel engine, although they were subsequently replaced by fossil fuels due to economic issues. To achieve a short-term energy transition process in the most efficient way, the substitution of fossil fuels by SVOs ought to be carried out, keeping the current fleet of compression-ignition (C.I.) Diesel engines. However, since diesel engines are designed to run on diesel fuel, the higher viscosity that vegetable oils exhibit reduces fuel atomization and generates problems in diesel engines, e.g., carbon depositions on the injector, less efficient combustion, etc. [7]. For this reason, in addition to the widely used transesterification reaction, alternative methodologies to adjust viscosity values of vegetable oils to those required by European norm EN 590, such as pyrolysis or emulsification, have recently been studied [8].

The technique of blending an SVO with a low-viscosity solvent (LVS) has gained a lot of attention from among the different options. In the literature, numerous works have reported the effect of adding a less viscous compound to vegetable oils to diminish their high viscosity. Thereby, gasoline has been successfully used to reduce the high viscosity of castor oil and sunflower oil in blends with fossil diesel [9]. However, in order to achieve a higher diesel replacement, compounds derived from renewable sources represent a better option. Generally, the use of oxygen-rich compounds as viscosity improvers allows to a better combustion process and reduced emissions. In this sense, light vegetable oils (orange, camphor, eucalyptus and pine oil) [10-13] and lower (methanol and ethanol) [14-16] and higher alcohols (1-propanol, 2-propanol, isobutanol, 1-butanol, 2-butanol and 1-pentanol) [16,17], as well as other renewable oxygenated compounds (diethyl ether, acetone, ethyl acetate, diethyl carbonate and so on) [18-21] have recently been described as viscosity reducers of SVOs. Overall, the exhaust emissions were significantly reduced with the use of these blends, resulting in a similar or slightly lower engine performance than that exhibited by conventional diesel. Moreover, the behavior of blends at low temperatures is usually improved by using these less viscous oxygenated compounds.

In this line, dimethyl carbonate is highlighted as a potential biofuel not only because of its non-toxic and biodegradable nature, but also because of its suitable properties for achieving a good performance in diesel engines, including high miscibility with diesel fuel, low boiling point and high oxygen content ( $53 \%$ by weight). Furthermore, the absence of carbon-carbon bonds in the dimethyl carbonate (DMC) molecule would contribute to hydrocarbon oxidation, which limits its participation in soot growth reactions [22]. Although DMC is industrially produced through different routes, e.g., phosgenation, transesterification or oxidative carbonylation of methanol using $\mathrm{O}_{2}$, another low-cost and higher efficiency alternative route that implies the use of $\mathrm{CO}_{2}$ as feedstock, is under study [23]. Thus, DMC can be directly produced from methanol and $\mathrm{CO}_{2}$ by catalytic procedures [24]. Methanol can also be obtained by catalytic hydrogenation of $\mathrm{CO}_{2}$ [25], which becomes DMC production in a $\mathrm{CO}_{2}$ sink, and contributes to the reduction of this harmful gas.

In recent years, DMC has been intensively studied as an effective biofuel and additive for diesel fuel [22,26-34]. This oxygenated compound has been tested in blends with biodiesel [35,36] and in biodiesel/diesel blends [37]. Results have showed that the use of DMC notably improves the engine performance and exhaust emissions from C.I. 
engines [22,26-37]. However, DMC has only been applied as an additive in small proportions to diesel, biodiesel or their blends because of its low calorific value that reduces the energy density of fuel mixtures, which represents the most important limitation of this methodology to reach high levels of fossil fuel substitution. In order to increase the percentage of replaced fossil diesel, the combination of renewable vegetable oils and DMC represents an excellent option.

To the best of our knowledge, the direct blending technique applied to vegetable oils and DMC as a solvent has not yet been studied. Herein, waste cooking oil (sunflower oil) and castor oil, two second-generation biofuels, have been chosen as SVOs due to their easy availability and lack of competition with food uses. Then, this work provides information about the castor oil/DMC and sunflower oil/DMC binary blends as substitute biofuels for fossil diesel. To evaluate the possibilities of using these pure vegetable oils and dimethyl carbonate as biofuels, the most important physico-chemical properties of fuel blends, as well as their efficiency in a conventional diesel engine, have been studied.

This paper firstly collects an analysis of viscosity, density, cold flow properties, cetane number and calorific value of the ternary fuel blends. Secondly, the evaluation of the performance of a diesel engine fueled with the proposed new fuels through relevant engine parameters, such as brake-specific fuel consumption (BSFC), power output and generated smoke emissions, has also been carried out.

\section{Materials and Methods}

Some of the most important physico-chemical properties of diesel, sunflower oil, castor oil and dimethyl carbonate (DMC) are collected in Table 1.

Table 1. Properties of diesel, sunflower oil, castor oil and dimethyl carbonate (DMC) [26-37]. Kinematic viscosity and density data are obtained from this work.

\begin{tabular}{ccccc}
\hline Property & Diesel & Sunflower Oil & Castor Oil & DMC \\
\hline Density at $15^{\circ} \mathrm{C}\left(\mathrm{kg} / \mathrm{m}^{3}\right)$ & 820 & 865 & 898 & 1079 \\
Kinematic viscosity at $40{ }^{\circ} \mathrm{C}(\mathrm{cSt})$ & 3.20 & 37.80 & 226.20 & 0.63 \\
Oxygen content $(\mathrm{wt} . \%)$ & 0 & 10 & 15 & 53 \\
Calorific value $(\mathrm{MJ} / \mathrm{L})$ & 35.1 & 34.3 & 35.5 & 17.0 \\
Flash point $\left({ }^{\circ} \mathrm{C}\right)$ & 66 & 220 & 228 & 21.7 \\
Auto-ignition temperature $\left({ }^{\circ} \mathrm{C}\right)$ & 250 & 316 & 448 & 220 \\
Cetane number & 51 & 37 & 40 & 35.5 \\
\hline
\end{tabular}

2.1. Preparation of (Bio)Fuel Blends: Dimethyl Carbonate/Vegetable Oil Binary Mixture, and Diesel/Dimethyl Carbonate/Vegetable Oil Ternary Mixture

Dimethyl carbonate (purity $\geq 99.5 \%$ ) was acquired from Sigma-Aldrich (St. Louis, MO, USA). Sunflower oil (as a reference for waste cooking oils) and castor oil were purchased from a local market and from Panreac (Castellar Del Valles, Spain), respectively. Diesel was acquired from a Repsol service station.

The DMC/SVO double blends were prepared by adding DMC to either sunflower or castor oil in proportions of 20,40, 45, 50 and $60 \%$ by volume. Those DMC/sunflower oil $\mathrm{SO}$ ) and $\mathrm{DMC} /$ castor oil (CO) double mixtures that met the viscosity requirements according to the EN-590 ISO-3104 standard were mixed with commercial diesel (diesel/DMC/SVO triple blends). The proportions of mixed fuels, in vol. $\%$, are as follows: $20 \% \mathrm{DMC} / \mathrm{SO}$ + 80\% diesel (B20SO), 40\% DMC/SO + 60\% diesel (B40SO), 60\% DMC/SO + 40\% diesel (B60SO), $80 \% \mathrm{DMC} / \mathrm{SO}+20 \%$ diesel (B80SO), 20\% DMC/CO + 80\% diesel (B20CO), $40 \%$ $\mathrm{DMC} / \mathrm{CO}+60 \%$ diesel (B40CO), 60\% DMC/CO + 40\% diesel (B60CO), 80\% DMC/CO + $20 \%$ diesel (B80CO). In addition, 100\% commercial diesel (B0) and pure biofuels composed of sunflower oil (DMC/SO, B100SO) and castor oil (DMC/CO, B100CO) were experimentally tested as reference fuels. 


\subsection{Fuel Characterization}

The most important physico-chemical properties of fuel blends for their use in a diesel engine, including kinematic viscosity, density, cloud point, pour point, calorific value and cetane number, are determined either by experimental testing or by using predictive equations. Herein, all data are displayed as an average of three experimental measures. Additionally, errors are indicated as the standard deviation.

\subsubsection{Kinematic Viscosity and Density}

The EN ISO 3675 test method was used for density measurements of diesel, DMC, SO, $\mathrm{CO}$ and their blends. The pure fuel components and the different blends were cooled until reaching a temperature of $15^{\circ} \mathrm{C}$ and, after that, the measurements were performed.

The EN 590 ISO 3104 test method was used for kinematic viscosity measures. Thus, kinematic viscosity $(v)$ was measured at $40{ }^{\circ} \mathrm{C}$ using an Ostwald-Cannon-Fenske capillary viscometer (Proton Routine Viscometer 33, 200, size 150). The viscosity, expressed in centistokes ( $\mathrm{cSt}$ ) or $\mathrm{mm}^{2} / \mathrm{s}$, was obtained by means of Equation (1):

$$
v=\mathrm{C} \cdot \mathrm{t}
$$

where $\mathrm{C}$ is the constant of the calibrated viscometer, provided by the manufacturer $(0.037150$ $\left(\mathrm{mm}^{2} / \mathrm{s}\right) / \mathrm{s}$ at $\left.40{ }^{\circ} \mathrm{C}\right)$ and $\mathrm{t}$ is the flow time, i.e., the time (seconds) that a known volume of liquid takes to pass, under action of gravity, between two marks indicated on an instrument [18-21]. The maximum absolute error in the viscosity measurements is $1.1 \%$ and that in the density measurements is $0.7 \%$.

\subsubsection{Cloud Point and Pour Point}

The flow properties at low temperatures were measured following the same procedure as described in previous works [18,19]. EN 23015/ASTM D2500 and ISO 3016/ASTM D97 were the standard methods followed for cloud point $(\mathrm{CP})$ and pour point $(\mathrm{PP})$, respectively.

\subsubsection{Calorific Value and Cetane Number}

Calorific value $(\mathrm{CV})$ and cetane number $(\mathrm{CN})$ were estimated through the following generic Formula (2) [28]:

$$
\mathrm{P}=\sum_{i} P i \cdot x i
$$

where $\mathrm{P}$ is the estimated property of the fuel mixture, $P i$ is the property of each component and $x i$ is volumetric fraction of each component in the mixture. The $\mathrm{CV}$ is expressed in megajoules per liter $(\mathrm{MJ} / \mathrm{L})$ from the experimental density obtained for each blend.

\subsection{Experimental Procedure for Testing (Bio)Fuel Blends in Diesel Engine-Electrogenerator Set}

A study of power output, brake-specific fuel consumption and smoke emissions was carried out in a diesel engine-electrogenerator set fueled with the proposed fuel blends, in order to analyze their efficiency. An experimental methodology that has been previously reported was followed [18-21] and the technical specifications of the employed engine are collected in Table 2. Likewise, the experimental methodology is illustrated in Figure 1.

The compression-ignition engine employed in this investigation was a 4-stroke and single-cylinder engine with cylinder dimensions of $78 \mathrm{~mm}$ bore and $67 \mathrm{~mm}$ stroke, and a forced air-cooling system with a flywheel fan. To evaluate the different fuel blends, all engine parameters remained identical in each test, i.e., there were no modificationsto the engine during the tests. Additionally, the measures were carried out with same engine operation conditions, changing only the engine load $(0,1,2,3,4$ and $5 \mathrm{~kW})$. The engine load means the power demanded to the engine. Electric hot plates of $1000 \mathrm{~W}$ were connected to the engine to apply the different loads. The volume of fuel employed in each test was $0.5 \mathrm{~L}$. To ensure comparability between the measurements, the engine ran for $20 \mathrm{~min}$ before each 
test. Additionally, between different fuel blends, the engine was fueled with diesel and kept running for $20 \mathrm{~min}$ to purge from the system the possible remaining fuel.

Table 2. Diesel engine-electrogenerator set specifications.

\begin{tabular}{cc}
\hline Model & AYERBE 4000 Diesel \\
\hline Alternator & LINZ-SP 10MF 4.2 KVA \\
Engine & YANMAR LN-70 \\
Type & Vertical cylinder, 4-cycle, air-cooled diesel engine \\
Combustion & Direct injection \\
Bore $\times$ Stroke & $78 \times 67 \mathrm{~mm}$ \\
Displacement & $320 \mathrm{~cm}^{3}$ \\
Horsepower & 6.7 \\
Rated power output & $4.5 \mathrm{~kW} / 3000 \mathrm{rpm}$ \\
Voltage & $230 \mathrm{~V}$ \\
Fuel consumption & $1.3 \mathrm{~L} / \mathrm{H}(75 \%)$ \\
\hline
\end{tabular}

\section{Diesel engine-electrogenerator set}

(a)

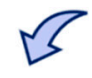

Power output

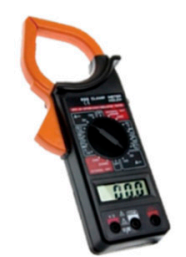

Voltmeter-ammeter

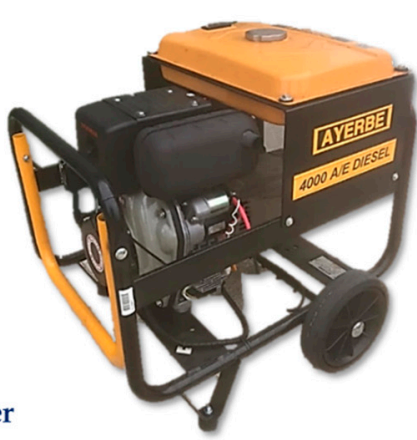

(b)

Soot emissions

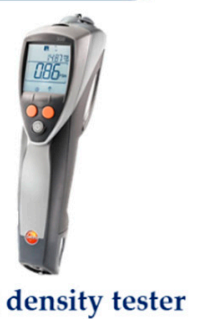

Figure 1. Scheme of experimental methodology to determine (a) power output by means of a voltmeter-ammeter device; (b) generated soot emissions by means of a smoke density tester, in a diesel engine-electrogenerator set [21].

The power output was calculated from the amperage and voltage generated by the engine, which were measured using a voltmeter-ammeter device.

The contamination degree was obtained from the opacity of the generated smoke during the combustion process. In this research, smoke density in the flue gases was measured with an opacimeter-type TESTO 338 density gauge (or smoke density tester), following the standard method ASTM D-2156. This instrument calculates the smoke density from the level of soot on a filter paper. The smoke emissions are expressed in soot concentration $\left(\mathrm{mg} / \mathrm{m}^{3}\right)$. The measurement range for smoke density is $0-50 \mathrm{mg} / \mathrm{m}^{3}$, where 0 indicates absolute clarity on the paper and 50 is maximum blackening. The repeatability is $\pm 0.5 \mathrm{mg} / \mathrm{m}^{3}$ (or $\pm 9 \%$ ). Before each test, the analyzer was calibrated with zero gas.

The BSFC, expressed in $\mathrm{g} / \mathrm{h} \cdot \mathrm{kW}$, is the mass of fuel consumed per hour and per $\mathrm{kW}$ of power generated by the engine. BSFC is calculated measuring the volume consumed by the engine fueled with the different (bio)fuels at a certain time. The BSFC measurements were carried out at engine loads of 1,3 and $5 \mathrm{~kW}$, which represent low, medium and high power demands. Experimental tests were done in triplicate, so the results are shown as the average of three measures. The errors are calculated as standard deviation and represented as error bars. mass of fuel consumed. 


\section{Results}

\subsection{Physico-Chemical Properties of Fuel Blends}

One of the most important properties of a fuel is the kinematic viscosity because it has a substantial influence on the atomization quality as well as the distribution of the fuel droplet size and uniformity of the mixture, which directly affects combustion. Therefore, the most suitable binary blends composed of DMC and sunflower or castor oils have been chosen based on this property. In this sense, the viscosity of each fuel blend must meet the European standard EN 590 ISO 3104, which establishes a viscosity range of 2.0-4.5 cSt for the appropriate running of a diesel engine.

In Table 3, the viscosity data sets of DMC/SVO double blends are collected. As can be seen, as the DMC proportion in the blend increased, the kinematic viscosity decreased. This demonstrated the positive effect of DMC to reduce the high viscosity of vegetable oils. In fact, a very notable reduction in viscosity values is achieved by the incorporation of $20 \%$ DMC. The sunflower oil suffers a drastic drop in its viscosity value, from 37.80 to 11.46 cSt, i.e., it is three times lower. The effect of adding DMC to the vegetable oils is even stronger on castor oil, which reduces its very high initial viscosity $(226.20 \mathrm{cSt})$ by six times (26.38 cSt). The results show that suitable viscosity values of 4.42 and $3.59 \mathrm{cSt}$ can be obtained by the addition of $40 \%$ and $45 \%$ DMC to sunflower and castor oil, respectively. Therefore, these double blends can be used as biofuels in a conventional diesel engine, according to European Standard requirements.

Table 3. Kinematic viscosity (cSt) at $40{ }^{\circ} \mathrm{C}$ of dimethyl carbonate (DMC)/sunflower oil (SO) and dimethyl carbonate $(\mathrm{DMC})$ / castor oil (CO) binary blends.

\begin{tabular}{|c|c|c|c|c|c|c|c|c|}
\hline \multirow{2}{*}{ Property } & \multirow{2}{*}{ Blend } & \multicolumn{7}{|c|}{ Dimethyl Carbonate (vol\%) } \\
\hline & & 0 & 20 & 40 & 45 & 50 & 60 & 100 \\
\hline \multirow{2}{*}{$\begin{array}{c}\text { KinematicViscosity } \\
\text { (cSt) }\end{array}$} & $\mathrm{DMC} / \mathrm{SO}$ & $37.80 \pm 0.46$ & $11.46 \pm 0.25$ & $4.49 \pm 0.02$ & $4.06 \pm 0.03$ & $3.52 \pm 0.06$ & $2.45 \pm 0.05$ & $0.63 \pm 0.02$ \\
\hline & $\mathrm{DMC} / \mathrm{CO}$ & $226.20 \pm 0.55$ & $26.38 \pm 0.09$ & $7.04 \pm 0.03$ & $4.31 \pm 0.02$ & $3.06 \pm 0.025$ & $2.15 \pm 0.10$ & $0.63 \pm 0.02$ \\
\hline
\end{tabular}

Some of the most important fuel properties of D/DMC/SVO triple blends, prepared by the combination of fossil diesel and the selected biofuels (DMC/SO 40/60 and DMC/CO $45 / 55$ ) have been determined, in order to evaluate their influence on performance of a diesel engine. All data related to kinematic viscosity, density, cloud point, pour point, calorific value and cetane number are collected in Tables 4 and 5 . As can be seen, as the percentage of DMC/SVO biofuel incorporated into diesel increased, from $20 \%$ to $80 \%$ (B20-B80), the viscosity also increases, which is logical due to the higher viscosity of the biofuels (4.49 and $4.31 \mathrm{cSt}$ ) with respect to diesel $(3.2 \mathrm{cSt})$. Overall, all the tested blends comply with the viscosity requirements indicated by European Standard EN 590, and so they are suitable fuels for fueling a C.I. diesel engine.

Table 4. Fuel properties of diesel (B0), DMC/SO double blend (B100) and diesel (D)/DMC/SO triple blends (B20-B80), containing $40 \%$ DMC.

\begin{tabular}{cccccccc}
\hline Fuel Blend & D/DMC/SO & $\begin{array}{c}\text { Kinematic } \\
\text { Viscosity }(\mathbf{c S t})\end{array}$ & $\begin{array}{c}\text { Density at 15 } \\
{ }^{\circ} \mathbf{C}\left(\mathbf{k g} / \mathbf{m}^{\mathbf{3}}\right)\end{array}$ & $\begin{array}{c}\text { Cloud Point } \\
\left({ }^{\circ} \mathbf{C}\right)\end{array}$ & $\begin{array}{c}\text { Pour Point } \\
\left({ }^{\circ} \mathbf{C}\right)\end{array}$ & $\begin{array}{c}\text { Calorific } \\
\text { Value }(\mathbf{M J} / \mathbf{L})\end{array}$ & $\begin{array}{c}\text { Cetane } \\
\mathbf{N u m b e r}\end{array}$ \\
\hline B0 & $100 / 0 / 0$ & $3.20 \pm 0.03$ & $820 \pm 6$ & $-6.0 \pm 1.0$ & $-16.0 \pm 1.2$ & 35.10 & 51.00 \\
B20SO & $80 / 8 / 12$ & $3.22 \pm 0.02$ & $850 \pm 5$ & $-9.0 \pm 1.2$ & $-19.5 \pm 0.8$ & 34.22 & 48.08 \\
B40SO & $60 / 16 / 24$ & $3.60 \pm 0.03$ & $864 \pm 4$ & $-8.0 \pm 1.1$ & $-18.1 \pm 1.0$ & 32.58 & 45.16 \\
B60SO & $40 / 24 / 36$ & $3.65 \pm 0.04$ & $909 \pm 3$ & $-5.7 \pm 0.6$ & $-14.3 \pm 1.1$ & 31.96 & 42.24 \\
B80SO & $20 / 32 / 48$ & $4.13 \pm 0.04$ & $939 \pm 4$ & $-5.2 \pm 0.9$ & $-13.2 \pm 0.9$ & 30.63 \\
B100SO & $0 / 40 / 60$ & $4.49 \pm 0.02$ & $960 \pm 5$ & $-4.5 \pm 1.0$ & $-12.3 \pm 1.0$ & 28.90 & 39.32 \\
\hline
\end{tabular}


Table 5. Fuel properties of diesel (B0), DMC/CO double blend (B100) and D/DMC/CO triple blends (B20-B80, containing $45 \%$ DMC.

\begin{tabular}{cccccccc}
\hline Fuel Blend & D/DMC/CO & $\begin{array}{c}\text { Kinematic } \\
\text { Viscosity }(\mathbf{c S t})\end{array}$ & $\begin{array}{c}\text { Density at 15 } \\
{ }^{\circ} \mathbf{C}\left(\mathbf{k g} / \mathbf{m}^{\mathbf{3}}\right)\end{array}$ & $\begin{array}{c}\text { Cloud Point } \\
\left({ }^{\circ} \mathbf{C}\right)\end{array}$ & $\begin{array}{c}\text { Pour Point } \\
\left({ }^{\circ} \mathbf{C}\right)\end{array}$ & $\begin{array}{c}\text { Calorific } \\
\text { Value }(\mathbf{M J} / \mathbf{L})\end{array}$ & $\begin{array}{c}\text { Cetane } \\
\mathbf{N u m b e r}\end{array}$ \\
\hline B0 & $100 / 0 / 0$ & $3.20 \pm 0.03$ & $820 \pm 6$ & $-6.0 \pm 1.0$ & $-16 \pm 1.2$ & 35.10 & 51.00 \\
B20CO & $80 / 9 / 11$ & $3.23 \pm 0.01$ & $856 \pm 5$ & $-12.0 \pm 0.8$ & $-20.5 \pm 0.5$ & 34.24 & 48.40 \\
B40CO & $60 / 18 / 22$ & $3.40 \pm 0.02$ & $877 \pm 5$ & $-10.0 \pm 1.0$ & $-19.0 \pm 0.7$ & 32.63 & 45.79 \\
B60CO & $40 / 27 / 33$ & $3.64 \pm 0.04$ & $919 \pm 5$ & $-9.3 \pm 0.9$ & $-16.4 \pm 0.7$ & 31.63 & 43.19 \\
B80CO & $20 / 36 / 44$ & $4.12 \pm 0.04$ & $946 \pm 4$ & $-7.4 \pm 0.8$ & $-15.9 \pm 0.4$ & 29.91 & 40.58 \\
B100CO & $0 / 45 / 55$ & $4.31 \pm 0.02$ & $979 \pm 5$ & $-8.0 \pm 0.6$ & $-15.3 \pm 1.0$ & 28.22 & 37.98 \\
\hline
\end{tabular}

The density is a property that has an impact on the power and the fuel spray characteristics of the engine and therefore on the engine performance, combustion and exhaust emissions. As was expected, the density values of ternary blends were increased with an increase in the proportion of dimethyl carbonate and vegetable oil due to their higher viscosity in comparison with diesel (see Table 1). Therefore, it is found that the density values of mixtures containing sunflower oil oscillate between 850 and $960 \mathrm{~kg} / \mathrm{m}^{3}$ (Table 4), whereas castor oil blends show densities within the range $856-979 \mathrm{~kg} / \mathrm{m}^{3}$ (Table 5).

In order to know the influence on the cold flow properties of blending DMC and vegetable oils with traditional fossil diesel, both the cloud point and pour point of each mixture were determined, and the results are displayed in Tables 3 and 4 . As can be observed, a small proportion of DMC (8-9\%) is able to reduce CP and PP values of the B20 mixtures by around $3.0-6.0^{\circ} \mathrm{C}$ and $3.5-4.5^{\circ} \mathrm{C}$, respectively. However, it is noted that those fuel mixtures containing an amount of DMC above 16-18\% (B60-B100) do not show significative improvements in the flow characteristic at low temperatures and, in some cases, CP and PP values even slightly increase (B60SO-B100SO and B100CO blends). The best results are obtained with the blends composed of castor oil. Particularly, B20CO exhibited the lowest $\mathrm{PP},-20.5^{\circ} \mathrm{C}$, and the biggest reduction of $\mathrm{CP},-12.0^{\circ} \mathrm{C}$ (by addition of $9 \%$ DMC and $11 \%$ castor oil). In general, enhancements in the $\mathrm{CP}$ and $\mathrm{PP}$, as compared to diesel, are produced by using up to $40 \%$ pure biofuel, independently of the vegetable oil employed. From the results of fuel characterization, it can be affirmed that the use of these new biofuels could solve the biodiesel problem associated with the poor low-temperature flow properties.

The calorific value of a fuel is an essential parameter of engine performance, since it is directly related with power output and fuel consumption. The effect of DMC on the calorific value of blends with diesel and sunflower oil (Table 4) or castor oil (Table 5) has been analyzed. As can be observed, a higher proportion of DMC/SVO biofuel into the blend involves a progressive decline in the calorific values of fuels. This tendency is ascribed to the increase in DMC in the mixtures, as the calorific value of dimethyl carbonate $(17.0 \mathrm{MJ} / \mathrm{L})$ is lower than diesel (35.1 MJ/L, Table 1). Therefore, the highest calorific value (around $34 \mathrm{MJ} / \mathrm{L}$ ) corresponds to the blends that contain the lowest percentage of DMC $(8-9 \%)$, i.e., B20 fuel mixtures (B20SO and B20CO). It is very remarkable that these blends have about $98 \%$ of the calorific value of diesel. For their part, B100SO and B100CO, i.e., the pure biofuels composed exclusively of DMC and vegetable oil, exhibit calorific values of 28.90 and $28.22 \mathrm{MJ} / \mathrm{L}$, respectively, and so they have around 18-20\% less energy than diesel. No big differences in energetic content are observed by comparing both vegetable oils. This fact was expected, considering that they have very close calorific values, $34.3 \mathrm{MJ} / \mathrm{L}$ for SO and $35.5 \mathrm{MJ} / \mathrm{L}$ for $\mathrm{CO}$ (Table 1). In general, triple fuel mixtures with sunflower oil exhibit up to $13 \%$ less energy than diesel fuel, while the analogous castor oil blends show a maximum energy loss of $15 \%$ in comparison with the fossil fuel.

Cetane number indicates the ignition quality of a fuel. Tables 4 and 5 also display the variation of cetane number with the volumetric percentage of DMC and vegetable oil in the triple blends. As can be seen, cetane number decreases as the DMC/SVO blending ratio rises from $20 \%$ to $100 \%$ for all mixtures. Particularly, mixtures composed of castor 
oil show slightly higher cetane number values than those with sunflower oil. The $\mathrm{CN}$ for B20SO-B100SO mixtures ranges between 48.08 and 36.40, whereas B20CO-B100CO mixtures exhibit a CN of 48.40-37.98. The European standard EN 14214 establishes that the $\mathrm{CN}$ should be at least 51 . Since all of studied fuels have a cetane number below 51 , a higher ignition delay is regarded as likely.

3.2. Performance of a Diesel Engine Fueled with Dimethyl Carbonate/Straight Vegetable Oil and Diesel/Dimethyl Carbonate/Straight Vegetable Oil (Bio)Fuel Mixtures

\subsubsection{Power Output}

Figure 2 shows the effect of the addition of DMC/SO (Figure 2a) and DMC/CO blends (Figure 2b), as pure biofuels (B100) or in triple blends with diesel (B20-B80), on the power output of a diesel engine at loads of 0 to $5 \mathrm{~kW}$. For comparison, fossil diesel (B0) tests have also been included as a reference. In most cases, the power output increased as engine load increased from 0 to $4 \mathrm{~kW}$, whereas a slight decrease in power output is produced when the load applied to the engine is $5 \mathrm{~kW}$. This behavior is observed for diesel and B20SO-B80SO blends that contain up to $80 \%$ biofuel, as well as B20CO-B60CO blends, composed of a maximum of $60 \% \mathrm{DMC} / \mathrm{CO}$ biofuel. On the contrary, the pure biofuel $\mathrm{B} 100 \mathrm{SO}$ and $\mathrm{B} 80 \mathrm{CO}-\mathrm{B} 100 \mathrm{CO}$ fuels exhibit a different tendency, since the generated power by the engine fueled with these fuels rises for engine loads from 0 to $3 \mathrm{~kW}$ and then suffers a gradual drop between 3 and $5 \mathrm{~kW}$.

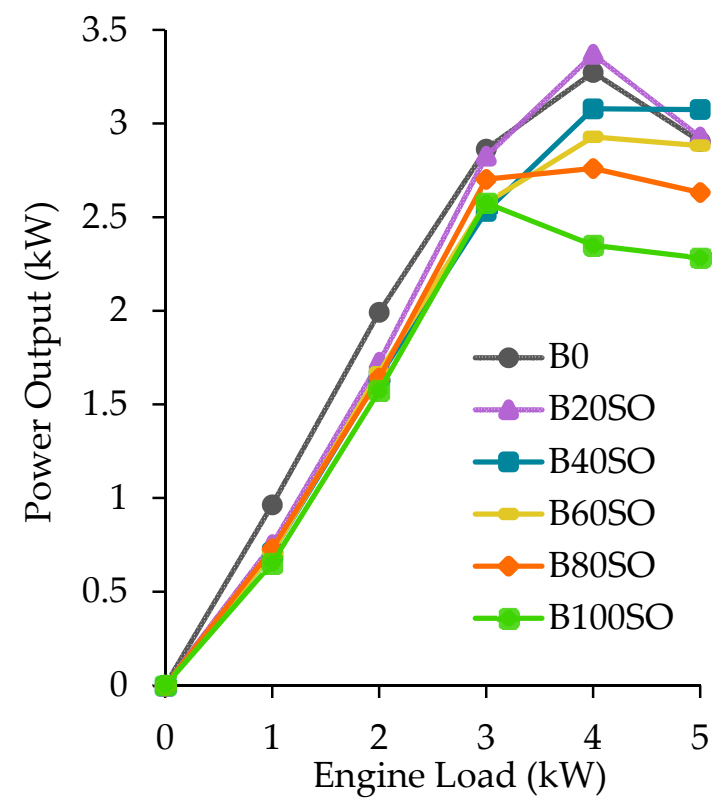

(a)

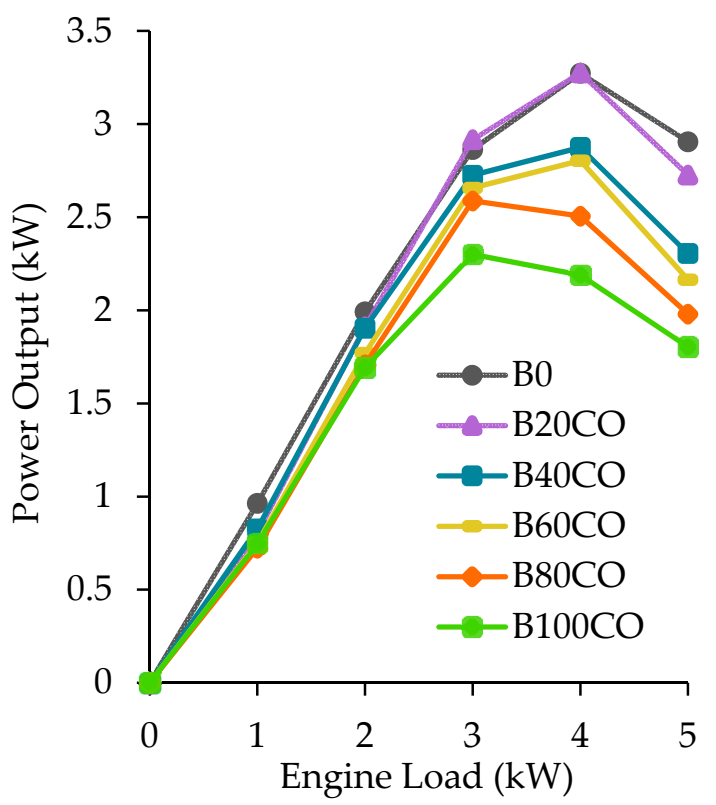

(b)

Figure 2. Effect of (a) DMC/SO and (b) DMC/CO biofuels on power output (W) of a diesel engine at different loads from 0 to $5 \mathrm{~kW}$. Measurement errors are less than $3 \%$ in all cases.

It can be observed that, independently of the SVO employed, an increment in the percentage of DMC/SVO biofuel (from B20 to B100) involves a lower power output with respect to diesel. This behavior is explained by the lower energetic content of fuel mixtures, as the ratio of dimethyl carbonate, whose calorific value (17 MJ/L) is about half that of diesel (35.1 MJ/L), gets larger. Although the loss of power can be mainly attributed to energy density, the effect of any other operational parameters on engine performance cannot be ruled out. Since the pure biofuels do not contain diesel and have the highest proportion of DMC, B100SO and B100CO generate the lowest power, up to $32 \%$ and $38 \%$ less power than diesel, respectively. However, engine operability fueled with the $100 \%$ renewable fuels (DMC/SVO double blends) should be highlighted. The best results are 
shown by B20SO and B20CO, probably because of their higher calorific value, higher cetane number, lower density and lower viscosity, in comparison with the rest of the blends. It is very outstanding that these fuels give rise to very similar power values to those of commercial diesel, and even slightly higher at the highest engine loads. This fact could be due to a better combustion resulting from using more oxygen-enriched fuels. In general, no significant differences between the two vegetable oils are noted since their mixtures exhibit a similar calorific value and cetane number (Tables 4 and 5).

\subsubsection{Brake-Specific Fuel Consumption (BSFC)}

BSFC is a key parameter to find the efficiency of an engine. The lower the BSFC for a given power output, the more efficient the engine will be. Figure 3 illustrates the variation in the BSFC at low $(1 \mathrm{~kW})$, medium $(3 \mathrm{~kW})$ and high $(5 \mathrm{~kW})$ engine loads, with the different $\mathrm{DMC} / \mathrm{SO}$ and D/DMC/SO blends (Figure 3a), as well as the DMC/CO and D/DMC/CO blends (Figure 3b). For all tested fuels, BSFC decreases as engine load becomes higher. Thus, the highest BSFC values are obtained at the lowest load. At medium loads, BSFC decreases and, afterwards, it remains practically constant at the highest load. This fact is associated with the higher temperature inside the cylinder that enhances the combustion process and so leads to a drop in the BSFC values as the engine load increases [38].

As can be observed in Figure $3 a, b$, the increase in \%DMC in triple mixtures promotes an increment in BSFC in comparison with diesel, because of its low calorific value (Table 1) that decreases the energy content of the blends. Additionally, other factors, such as a higher density and higher viscosity, as DMC content is increased from B20 to B100, lead to an increase in BSFC because a greater quantity of fuel is required by the engine to produce the same power. Therefore, all of blends show higher BSFC than diesel. Nonetheless, there are no big variations in BSFC for the fuel mixtures at $3 \mathrm{~kW}$ and $5 \mathrm{~kW}$. Indeed, BSFC for B20 and B40 is very similar to that of diesel, independent of vegetable oil, which is mainly due to the oxygen-rich content of the tested fuels that improves the premixed combustion phase, resulting in an increment in power output and lower BSFC. On the other hand, the use of sunflower or castor oil does not result in noteworthy differences, since the properties of the tested blends are very similar (Tables 4 and 5). The smaller BSFC revealed by the sunflower oil mixtures, in comparison with their counterparts with castor oil, could be a consequence of their slightly lower cetane number, which prolongs the ignition delay, contributing to a better premixed combustion phase [31].

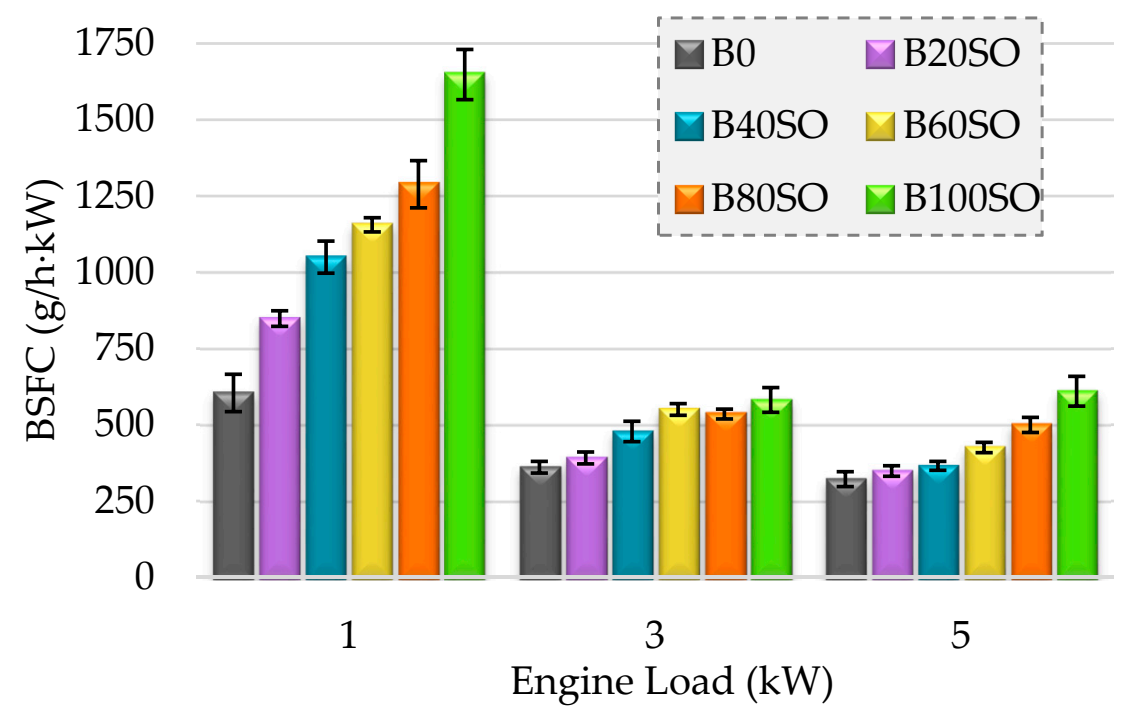

(a)

Figure 3. Cont. 


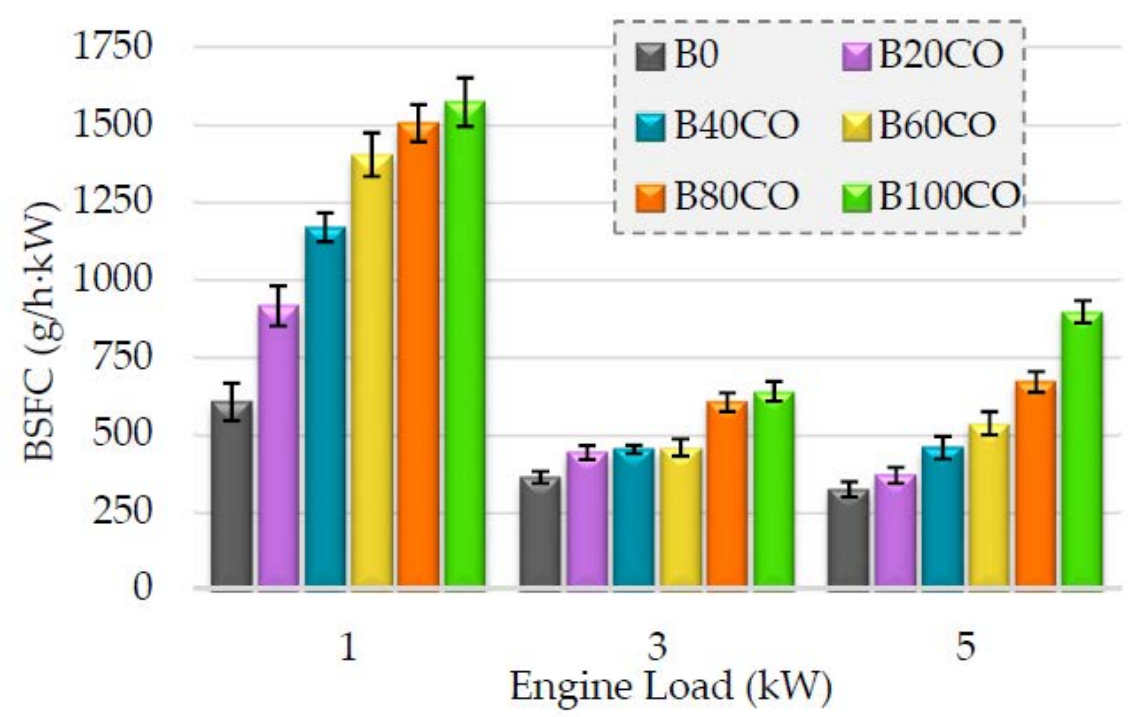

Figure 3. Effect of (a) DMC/SO and (b) DMC/CO biofuels on BSFC $(\mathrm{g} / \mathrm{h} \cdot \mathrm{kW}$ ) at low, medium and high engine loads $(1,3,5 \mathrm{~kW})$. The measurement errors are represented as standard deviation using error bars.

\subsection{Exhaust Emissions from Diesel Engine: Smoke Opacity}

The smoke opacity values versus engine load for B20SO-B100SO (Figure 4a) and B20CO-B100CO (Figure 4b) blends are plotted in Figure 4. For all D/DMC/SVO blends, the results clearly reveal a significant reduction in smoke emissions at any engine load, as compared to those of conventional diesel. The higher the ratio of DMC/SVO biofuel in the triple blends, the higher the reduction of smoke emissions at all engine loads. This indicates that the enrichment of oxygen provided to fuel blends with the incorporation of DMC (53 wt.\% oxygen) enhances the combustion and, hence, reduces opacity. Generally, the presence of oxygen favors the oxidation of carbon to $\mathrm{CO}$ and $\mathrm{CO}_{2}$, rather than participates in soot growth reactions. In this sense, the radical $\mathrm{CH}_{3} \mathrm{OC} \bullet=\mathrm{O}$ from DMC decomposition usually leads to the formation of $\mathrm{CO}$ or $\mathrm{CO}_{2}$. Likewise, oxygenated fuels increase the formation of free radicals such as ${ }^{\bullet} \mathrm{O}$ and ${ }^{\bullet} \mathrm{OH}$ that promote the oxidation of unsaturated species, which are soot precursors [22]. On the other hand, in particular for the case of dimethyl carbonate, the absence of $\mathrm{C}-\mathrm{C}$ bonds in its structure reduces the formation of acetylene and benzene, which are species that lead to the formation of polycyclic aromatic hydrocarbons (PAHs), which are soot precursors [22,29]. Additionally, decreasing the cetane number of blends by the addition of DMC increases the ignition delay, which means that a major amount of fuel is burned during the premixed combustion phase and, therefore, soot particle oxidation is increased. This causes a decrease in the smoke from the engine as more biofuel is incorporated in the triple mixtures [29,39].

As is logical, the biofuels B100SO and B100CO that contain the highest percentage of oxygen and the lowest cetane number show the lowest opacity values at all loads, up to 96-97\% lower than that of diesel. In the triple blend cases, the highest opacity reduction is generally achieved at the lowest engine loads (1 and $2 \mathrm{~kW})$. Overall, an engine fueled with sunflower oil blends (B20SO-B80SO) emits between 3\% (B20SO at $3 \mathrm{~kW}$ ) and 78\% (B80SO at $1 \mathrm{~kW}$ ) less soot than diesel. For their part, fuels with castor oil as the vegetable oil (B20CO-B80CO) generate between 41\% (B20CO at $4 \mathrm{~kW}$ ) and $97 \%$ (B80CO at $1 \mathrm{~kW}$ ) less emissions than commercial diesel. Related to the kind of vegetable oil, the mixtures that contain castor oil emit less smoke than those containing sunflower oil at all loads. In fact, $20 \%$ biofuel (B20CO) is enough to notably lower opacity values down to $41-85 \%$ as compared to diesel, and down to $17-80 \%$ with respect to their counterparts with SO. The differences between both SVOs can be ascribed to the greater amount of unsaturations in the linoleic acid of sunflower oil, in comparison with those that the ricinoleic acid of $\mathrm{CO}$ incorporates in its structure. The unsaturated compounds are decomposed to PAHs, which 
are finally transformed into soot particles [40]. This would explain why the fuels containing sunflower oil have worse performance in reducing smoke opacity from a diesel engine. 


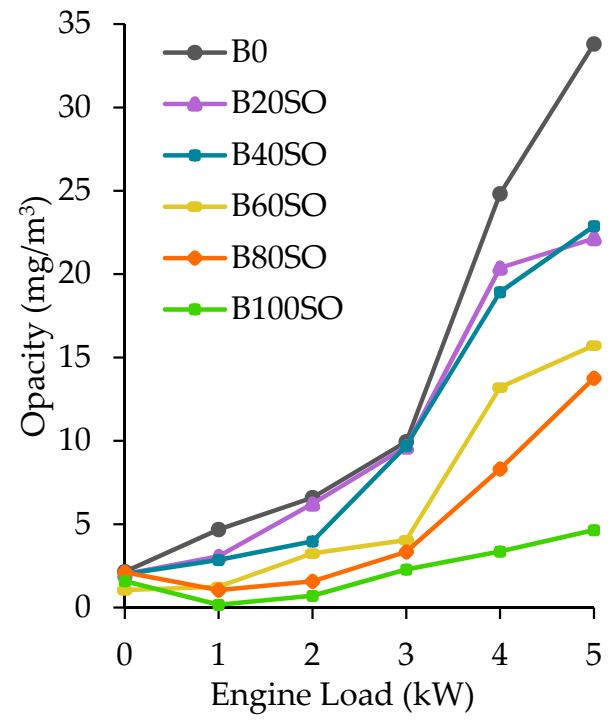

(a)

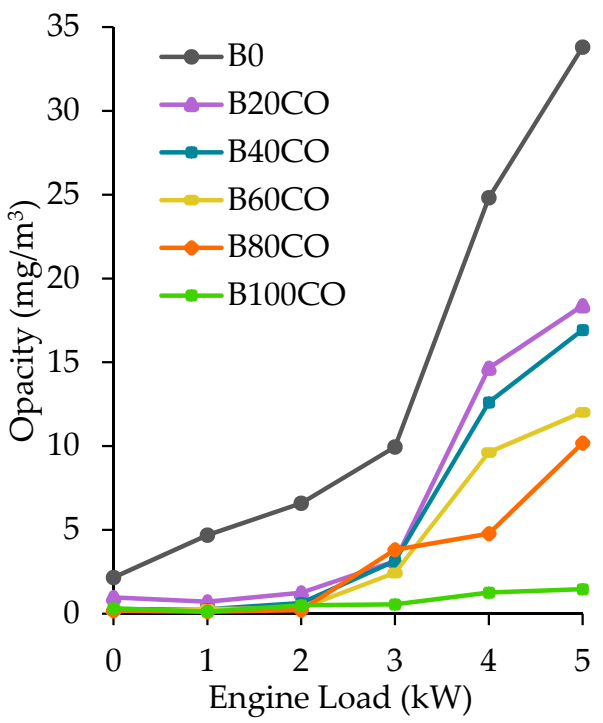

(b)

Figure 4. Effect of (a) DMC/SO and (b) DMC/CO biofuels on opacity $\left(\mathrm{mg} / \mathrm{m}^{3}\right)$ at engine loads from 0 to $5 \mathrm{~kW}$.

The implementation of the strategy studied here would not only reduce soot from the transportation sector, but could also be part of carbon capture, use and storage (CCUS) technology for the treatment of anthropogenic $\mathrm{CO}_{2}$ [41], since DMC can be synthetized from $\mathrm{CO}_{2}$ as a starting material.

\section{Conclusions}

This study has been conducted to evaluate the viability of dimethyl carbonate as a biofuel that is part of diesel/dimethyl carbonate/straight vegetable oil ternary blends. The effect of DMC on the blends has been studied through their application in a C.I. diesel engine. DMC successfully reduces the viscosity values of vegetable oils down to the limits required by the European Standard EN 590 on their usage in current diesel engines. Moreover, the use of DMC leads to an enhancement in cloud point and pour point values for blends B20SO-B40SO and B20CO-B80CO, especially in the cases where a maximum of $40 \%$ biofuel is added to diesel and castor oil is used as an SVO. Therefore, engines fueled with these blends can run more effectively in cold climates than with diesel and biodiesel, which provides a very important competitive advantage over other alternative fuels.

The reduction of calorific value and cetane number, as well as the increment in the density and viscosity as the biofuel amount is increased in the blends, from B20 to B100, are responsible for a lower power output and higher BSFC in comparison with diesel. However, the higher oxygen proportion in the blends improves the combustion and leads to a practically identical behavior to diesel for B20SO and B20CO blends. The higher oxygen content of fuels is also a key parameter to remarkably reduce smoke emissions by $97 \%$. The absence of carbon-carbon bonds in DMC and its tendency to decompose into CO and $\mathrm{CO}_{2}$ make this oxygenated compound an excellent candidate as a biofuel to reduce soot particles. Based on the studied criteria, the best engine efficiency is reached by B20CO containing $9 \% \mathrm{DMC}$ and $11 \% \mathrm{CO}$.

The results demonstrate that the blending procedure with DMC as a renewable solvent is a simple but effective method to allow the direct use of vegetable oils, avoiding the energy and economic costs associated with chemical transformation processes used to produce biodiesel, and, in this way, achieve higher levels of fossil fuel substitution as well as significantly reduced exhaust emissions, while keeping a very good engine performance. 
Author Contributions: D.L. designed the study; L.A.-D. performed the experiments and wrote the paper; R.E. reviewed and edited the paper; R.E., D.L. and F.M.B. supervised the study and revised the manuscript; C.L., J.H.-C., J.C., A.P. and A.A.R. made intellectual contributions to this study. All authors have read and agreed to the published version of the manuscript.

Funding: This research received no external funding.

Institutional Review Board Statement: Not applicable.

Informed Consent Statement: Not applicable.

Data Availability Statement: Not applicable.

Acknowledgments: The authors are thankful to MINECO-ENE2016-81013-R (AEI/FEDER, EU), MICIIN (Project ref. PID2019-104953RB-100), the Consejería de Transformación Económica, Industria, Conocimiento y Universidades de la Junta de Andalucía (UCO-FEDER Project CATOLIVAL, ref. 1264113-R, 2018 call and Project ref. P18-RT-4822) and FEDER Funds for financial support. Technical assistance of staff at the Central Service for Research Support (SCAI) and the Institute of Nanochemistry (IUNAN) of the University of Córdoba is also acknowledged.

Conflicts of Interest: The authors declare no conflict of interest.

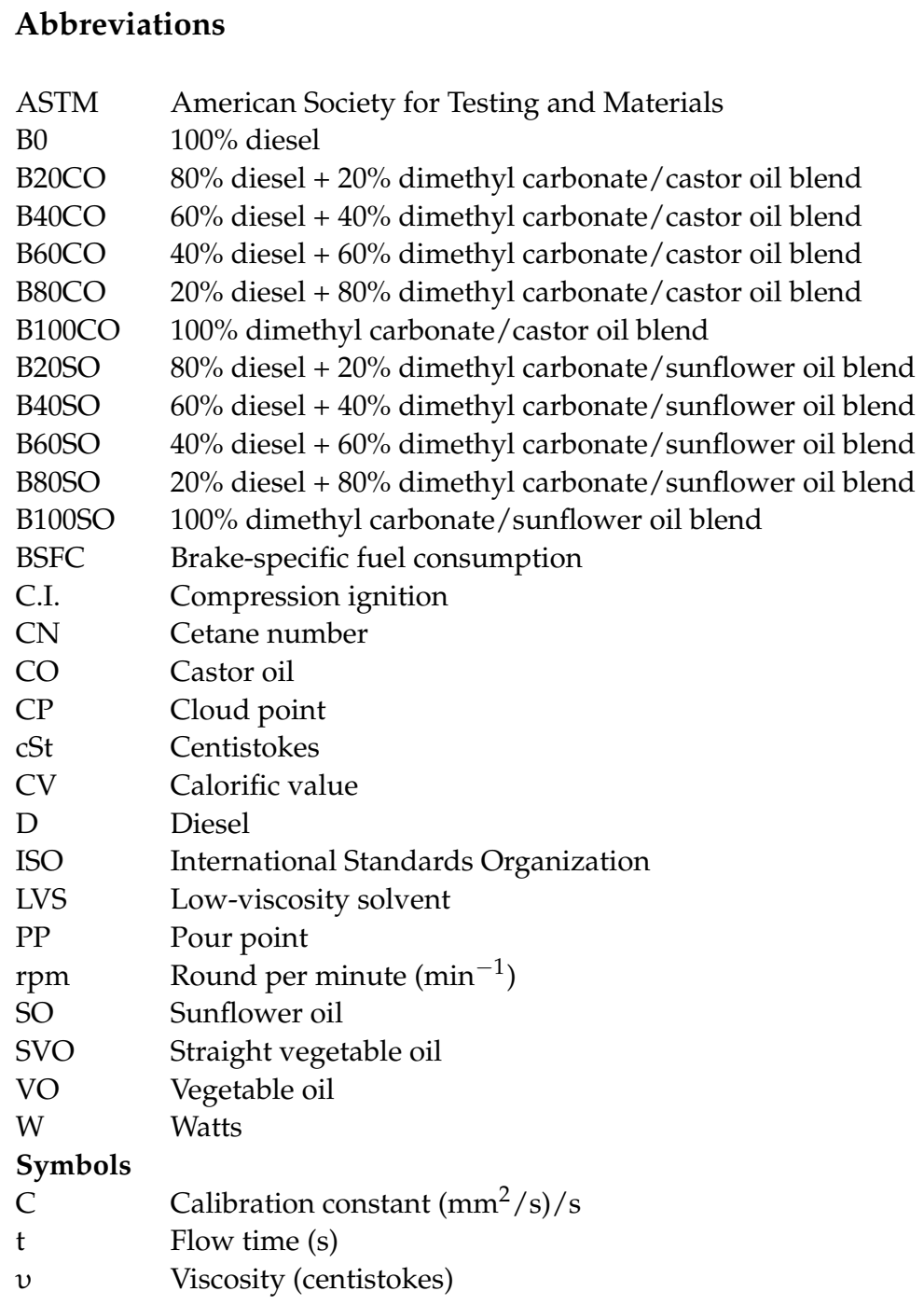




\section{References}

1. Nogueira, L.A.H.; Souza, G.M.; Cortez, L.A.B.; Brito Cruz, C.H.D. Biofuels for transport. In Future Energy, 3rd ed.; Letcher, T.M., Ed.; Elsevier: Amsterdam, The Netherlands, 2020; pp. 173-197. [CrossRef]

2. Sen, B.; Ercan, T.; Tatari, O. Does a battery-electric truck make a difference?-Life cycle emissions, costs, and externality analysis of alternative fuel-powered Class 8 heavy-duty trucks in the United States. J. Clean. Prod. 2017, 141, 110-121. [CrossRef]

3. Wang, M.; Dewil, R.; Maniatis, K.; Wheeldon, J.; Tan, T.; Baeyens, J.; Fang, Y. Biomass-derived aviation fuels: Challenges and perspective. Prog. Energy Combust. Sci. 2019, 74, 31-49. [CrossRef]

4. Winnes, H.; Styhre, L.; Fridell, E. Reducing GHG emissions from ships in port areas. Res. Transp. Bus. Manag. 2015, 17, 73-82. [CrossRef]

5. Mahlia, T.M.I.; Syazmi, Z.A.H.S.; Mofijur, M.; Pg-Abas, A.E.; Bilad, M.R.; Ong, H.C.; Silitonga, A.S. Patent landscape review on biodiesel production: Technology updates. Renew. Sustain. Energy Rev. 2020, 118, 1-9. [CrossRef]

6. Estevez, R.; Aguado-Deblas, L.; Bautista, F.M.; Luna, D.; Luna, C.; Calero, J.; Posadillo, A.; Romero, A.A. Biodiesel at the crossroads: A critical review. Catalysts 2019, 9, 1033. [CrossRef]

7. Misra, R.D.; Murthy, M.S. Straight vegetable oils usage in a compression ignition engine: A review. Renew. Sustain. Energy Rev. 2010, 14, 3005-3013. [CrossRef]

8. Abbaszaadeh, A.; Ghobadian, B.; Omidkhah, M.R.; Najafi, G. Current bio-diesel production technologies: A comparative review. Energy Convers. Manag. 2012, 63, 138-148. [CrossRef]

9. Estevez, R.; Aguado-Deblas, L.; Posadillo, A.; Hurtado, B.; Bautista, F.; Hidalgo, J.M.; Luna, C.; Calero, J.; Romero, A.; Luna, D. Performance and emission quality assessment in a diesel engine of straight castor and sunflower vegetable oils, in diesel/gasoline/oil triple blends. Energies 2019, 12, 2181. [CrossRef]

10. Martin, M.L.J.; Geo, V.E.; Singh, D.K.J.; Nagalingam, B. A comparative analysis of different methods to improve the performance of cotton seed oil fueled diesel engine. Fuel 2012, 102, 372-378. [CrossRef]

11. Kasiraman, G.; Nagalingam, B.; Balakrishnan, M. Performance, emission and combustion improvements in a direct injection diesel engine using cashew nut shell oil as fuel with camphor oil blending. Energy 2012, 47, 116-124. [CrossRef]

12. Kommana, S.; Banoth, B.N.; Kadavakollu, K.R. Eucalyptus-palm kernel oil blends: A complete elimination of diesel in a 4-stroke VCR diesel engine. J. Combust. 2015, 2015, 182879-182886. [CrossRef]

13. Prakash, T.; Geo, V.E.; Martin, L.J.; Nagalingam, B. Evaluation of pine oil blending to improve the combustion of high viscous (castor oil) biofuel compared to castor oil biodiesel in a CI engine. Heat Mass Transf. 2019, 55, 1491-1501. [CrossRef]

14. Senthil, M.K.; Ramesh, A.; Nagalingam, B. An experimental comparison of methods to use methanol and Jatropha oil in a compression ignition engine. Biomass Bioenergy 2003, 25, 309-318. [CrossRef]

15. Savariraj, S.; Ganapathy, T.; Saravanan, C.G. Performance and emission characteristics of diesel engine using high-viscous vegetable oil. Int. J. Ambient Energy 2012, 33, 193-203. [CrossRef]

16. Hurtado, B.; Posadillo, A.; Luna, D.; Bautista, F.; Hidalgo, J.; Luna, C.; Calero, J.; Romero, A.; Estevez, R. Synthesis, performance and emission quality assessment of ecodiesel from castor oil in diesel/biofuel/alcohol triple blends in a diesel engine. Catalysts 2019, 9, 40. [CrossRef]

17. Laza, T.; Bereczky, A. Basic fuel properties of rapeseed oil-higher alcohols blends. Fuel 2011, 90, 803-810. [CrossRef]

18. Aguado-Deblas, L.; Hidalgo-Carrillo, J.; Bautista, F.; Luna, D.; Luna, C.; Calero, J.; Posadillo, A.; Romero, A.; Estevez, R. Diethyl ether as an oxygenated additive for fossil diesel/vegetable oil blends: Evaluation of performance and emission quality of triple blends on a diesel engine. Energies 2020, 13, 1542. [CrossRef]

19. Aguado-Deblas, L.; Hidalgo-Carrillo, J.; Bautista, F.; Luna, D.; Luna, C.; Calero, J.; Posadillo, A.; Romero, A.; Estevez, R. Acetone prospect as an additive to allow the use of castor and sunflower oils as drop-in biofuels in diesel/acetone/vegetable oil triple blends for application in diesel engines. Molecules 2020, 25, 2935. [CrossRef]

20. Aguado-Deblas, L.; Estevez, R.; Hidalgo-Carrillo, J.; Bautista, F.M.; Luna, C.; Calero, J.; Posadillo, A.; Romero, A.A.; Luna, D. Outlook for direct use of sunflower and castor oils as biofuels in compression ignition diesel engines, being part of diesel/ethyl acetate/straight vegetable oil triple blends. Energies 2020, 13, 4836. [CrossRef]

21. Aguado-Deblas, L.; Hidalgo-Carrillo, J.; Bautista, F.; Luna, C.; Calero, J.; Posadillo, A.; Romero, A.; Luna, D.; Estevez, R. Biofuels from diethyl carbonate and vegetable oils for use in triple blends with diesel fuel: Effect on performance and smoke emissions of a Diesel engine. Energies 2020, 13, 6584. [CrossRef]

22. Yang, J.; Jiang, Y.; Karavalakis, G.; Johnson, K.C.; Kumar, S.; Cocker, D.R., III; Durbin, T.D. Impacts of dimethyl carbonate blends on gaseous and particulate emissions from a heavy-duty diesel engine. Fuel 2016, 184, 681-688. [CrossRef]

23. Tan, H.-Z.; Wang, Z.-Q.; Xu, Z.-N.; Sun, J.; Xu, Y.-P.; Chen, Q.-S.; Chen, Y.; Guo, G.-C. Review on the synthesis of dimethyl carbonate. Catal. Today 2018, 316, 2-12. [CrossRef]

24. Poungsombate, A.; Imyen, T.; Dittanet, P.; Embley, B.; Kongkachuichay, P. Direct synthesis of dimethyl carbonate from $\mathrm{CO}_{2}$ and methanol by supported bimetallic Cu-Ni/ZIF-8 MOF catalysts. J. Taiwan Inst. Chem. Eng. 2017, 80, 16-24. [CrossRef]

25. Martin, O.O.; Martín, A.J.; Mondelli, C.; Mitchell, S.; Segawa, T.F.; Hauert, R.; Drouilly, C.; Curulla-Ferré, D.; Pérez-Ramírez, J. Indium oxide as a superior catalyst for methanol synthesis by $\mathrm{CO}_{2}$ hydrogenation. Angew. Chem. Int. Ed. 2016, 55, 6261-6265. [CrossRef]

26. Sharan, P.; Bhaskaran, A.; Kalpana, S.; Ramesh, B.A. Effect of dimethyl carbonate on performance and emission characteristics of a diesel engine. Int. J. Curr. Res. Rev. 2018, 10, 116-121. [CrossRef] 
27. Rounce, P.; Tsolakis, A.; Leung, P.; York, A.P.E. A comparison of diesel and biodiesel emissions using dimethyl carbonate as an oxygenated additive. Energy Fuels 2010, 24, 4812-4819. [CrossRef]

28. Zhang, G.; Liu, H.; Xia, X.; Zhang, W.; Fang, J. Effects of dimethyl carbonate fuel additive on diesel engine performances. Proc. Inst. Mech. Eng. Part D J. Automob. Eng. 2005, 219, 897-903. [CrossRef]

29. Cheung, C.; Zhu, R.; Huang, Z. Investigation on the gaseous and particulate emissions of a compression ignition engine fueled with diesel dimethyl carbonate blends. Sci. Total Environ. 2011, 409, 523-529. [CrossRef]

30. Mei, D.; Hielscher, K.; Baar, R. Study on combustion process and emissions of a single cylinder diesel engine fueled with DMC/diesel blend. J. Energy Eng. 2014, 140, 04013004. [CrossRef]

31. Huang, Z.H.; Jiang, D.M.; Zeng, K.; Liu, B.; Yang, Z.L. Combustion characteristics and heat release analysis of a direct injection compression ignition engine fuelled with diesel-dimethyl carbonate blends. Proc. Inst. Mech. Eng. Part. D J. Automob. Eng. 2003, 217, 595-606. [CrossRef]

32. Pan, M.; Qian, W.; Huang, R.; Tong, C.; Huang, H.; Xu, L.; Hao, B. Effects of dimethyl carbonate and 2-ethylhexyl nitrate on energy distribution, combustion and emissions in a diesel engine under different load conditions. Energy Convers. Manag. 2019, 199, 111985. [CrossRef]

33. Lu, X.; Yang, J.; Zhang, W.; Huang, Z. Improving the combustion and emissions of direct injection compression ignition engines using oxygenated fuel additives combined with a cetane number improver. Energy Fuel 2005, 19, 1879-1888. [CrossRef]

34. Cheung, C.S.; Lee, S.C.; Kwok, A.; Tung, C.W. Effect of dimethyl carbonate blended diesel on emissions of a 4-cylinder diesel enginee. HKIE Trans. 2005, 12, 15-20. [CrossRef]

35. Nayak, S.K.; Mishra, P.C. Application of neem biodiesel and dimethyl carbonate as an alternative fuel. Energy Sources Part A Recovery Util. Environ. Eff. 2017, 39, 284-290. [CrossRef]

36. Nayak, S.K.; Mishra, P.C. Experimental investigation on performance and emission characteristics of a diesel engine fuelled with mahua biodiesel using additive. Energy Procedia 2014, 54, 569-579. [CrossRef]

37. Jayabal, R.; Thangavelu, L.; Subramani, S. Combined effect of oxygenated additives, injection timing and EGR on combustion, performance and emission characteristics of a CRDi diesel engine powered by sapota biodiesel/diesel blends. Fuel 2020, 276, 118020-118032. [CrossRef]

38. Venugopal, T.; Ramesh, A. Effective utilisation of butanol along with gasoline in a spark ignition engine through a dual injection system. Appl. Therm. Eng. 2013, 59, 550-558. [CrossRef]

39. Alexandrino, K.; Salinas, J.; Millera, Á.; Bilbao, R.; Alzuet, M.U. Sooting propensity of dimethyl carbonate, soot reactivity and characterization. Fuel 2016, 183, 64-72. [CrossRef]

40. Salamanca, M.; Mondragón, F.; Agudelo, J.R.; Benjumea, P.; Santamaría, A. Variations in the chemical composition and morphology of soot induced by the unsaturation degree of biodiesel and a biodiesel blend. Combust. Flame 2012, 159, 1100-1108. [CrossRef]

41. Núñez-López, V.; Gil-Egui, R.; Hosseini, S. Environmental and operational performance of $\mathrm{CO}_{2}$-EOR as a CCUS Technology: A cranfield example with dynamic LCA considerations. Energies 2019, 12, 448. [CrossRef] 